\title{
Optimization of coating material for encapsulation of flax seed oil containing omega-3 fatty acids
}

\author{
Dinesh Chandra Rai, Arvind and Vinod Kumar Paswan
}

Department of Dairy Science and Food Technology, Institute of Agricultural Sciences, Banaras Hindu University, Varanasi-221005, Uttar Pradesh, India

\begin{tabular}{l} 
Article Info \\
\hline Article history \\
Received 5 July 2020 \\
Revised 22 August 2020 \\
Accepted 25 August 2020 \\
Published online 30 December 2020
\end{tabular}

\section{Keywords}

Encapsulation

Maltodextrin

Sodium alginate

Spray dryer

\begin{abstract}
This study is aimed to evaluate the potential of different wall materials for microencapsulation of flaxseed oil containing omega-3 fatty acids by spray drying. Maltodextrin (MD) was mixed with Sodium Caseinate (SC), Sodium Alginate (SA) and Gum Acacia (GA), at three different ratios including 5:2, 5:4 and 5:6. The feed emulsions used for particle production were characterized for stability, particle size, zeta potential analysis and encapsulated powder were characterized for encapsulation yield, encapsulation efficiency and scanning electron microscope analysis. Best encapsulation efficiency was obtained for MD: SC which was followed by the MD: SA, while the lowest encapsulation efficiency was obtained for MD: GA, which also showed poorest emulsion stability.
\end{abstract}

\section{Introduction}

Over the past decade, the demand for wholesome and nutritious food has been increased remarkably (Rajeshwari et al., 2014). Flaxseed oil is a potent source of omega-3 fatty acid and gaining more attention towards nutritive food with several potential advantages to the food industry. Microencapsulation of omega-3 fatty acid rich flaxseed oil protects the core material by limiting its nutrient loss and converts it into a dispersed powder form (Desai and Park, 2005). The process of microencapsulation implies surface coating of active droplets of core material within coating material comprised of polysaccharides, lipids, and proteins to form microcapsules of micron to millimeter size range (Tyagi et al., 2011). Amongst the various microencapsulation techniques such as spray drying, freeze-drying, coacervation, and extrusion, generally spray drying technique is chosen because of its cheaper production cost (Desai and Park, 2005). The selection of coating material impersonates an influential part in the microencapsulation, as it shows a high impact on the stability of microcapsules, encapsulation efficiency, and the degree of protection to the core material. To achieve high encapsulation efficiency a combination of polysaccharides and proteins must be used for the production of microcapsules, as they both together shows synergistic effect, in which polysaccharides act as a matrix forming material and proteins act as emulsifying and film forming material (Gharsallaoui et al.,

Corresponding author: Dr. Arvind

Assistant Professor, Department of Dairy Science and Food Technology, Institute of Agricultural Sciences, Banaras Hindu University, Varanasi221005, Uttar Pradesh, India

E-mail: arvind1@bhu.ac.in

Tel.: +91-9793583702

Copyright $(\odot) 2020$ Ukaaz Publications. All rights reserved.

Email: ukaaz@yahoo.com; Website: www.ukaazpublications.com
2010; Mishra et al., 2020; Nesterenko et al., 2013). Polysaccharides used are maltodextrins, starches, sodium alginate, pectin, and chitosan whereas both animal protein (e.g., whey, gelatin, and casein) and plant protein (e.g., soy and pea) are used as a coating material. Omega fatty acid (omega-3, -6 , and -9) plays an essential role in prevention of several human diseases such as cardiovascular diseases, immune response disorders and maintenance of mental health (Shibasaki et al., 1999). Flaxseed oil comprising omega-3 fatty acid is unsaturated because of which it is chemically unstable and consequently becomes susceptible to oxidative deterioration leading to the production of free radicals, which thus affects the shelf-life, sensory attributes, and overall acceptability of food products (Velasco et al., 2000). Hence, microencapsulation of flaxseed oil provides an efficient way to minimize the susceptibility of flaxseed oil to various environmental parameters such as oxygen, light, temperature, and moisture, and thus enhances the product shelf-life and mask the undesirable taste and odor (Calvo et al., 2012).

The research was conducted with the aim to encapsulate the omega- 3 fatty acid rich flaxseed oil by spray drying and to evaluate the potential of a different combination of wall materials (including maltodextrin (MD), sodium caseinate (SC), sodium alginate (SA) and gum acacia (GA) to produce stable microcapsules.

\section{Materials and Methods}

\subsection{Materials}

Flaxseed oil (Ceyon Healthcare India Private Limited, Lucknow, India) was used as active material. The edible grade wall materials used were: Maltodextrin, Sodium Caseinate, Gum Acacia and Sodium Alginate (Himedia, India). 


\subsection{Emulsion preparation}

Encapsulation of omega-3 fatty acid rich flaxseed oil was done by using three combinations of maltodextrin with three wall materials sodium caseinate, sodium alginate, and gum acacia with total nine treatments (Table 1). The wall material firstly added to distilled water at $25^{\circ} \mathrm{C}$ then the mixture was agitated until completely dissolved. The total solid concentration (wall material + oil) was set to $30 \%$. Flaxseed oil was then added to the wall material solution at a concentration of $20 \%$ with respect to total solids (Ahn et al., 2008; Jafari et al., 2008; Charve and Reineccius, 2009). Emulsions were formed using an IKA T25 Digital Ultra-Turrax homogenizer (IKA, Germany) operating at 18,000 rpm for $5 \mathrm{~min}$.

Table 1: Different combinations of wall material for encapsulation of flex seed oil

\begin{tabular}{|l|l|l|l|}
\hline Treatments & Combination of wall material & $\begin{array}{l}\text { Ratio of wall } \\
\text { material }\end{array}$ & $\begin{array}{l}\text { Flax seed } \\
\text { oil (g) }\end{array}$ \\
\hline $\mathrm{T}_{1}$ & Maltodextrin + Sodium caseinate & $5: 2$ & 8 \\
$\mathrm{~T}_{2}$ & Maltodextrin + Sodium caseinate & $5: 4$ & 8 \\
$\mathrm{~T}_{3}$ & Maltodextrin + Sodium caseinate & $5: 6$ & 8 \\
$\mathrm{~T}_{4}$ & Maltodextrin + Sodium alginate & $5: 2$ & 8 \\
$\mathrm{~T}_{5}$ & Maltodextrin + Sodium alginate & $5: 4$ & 8 \\
$\mathrm{~T}_{6}$ & Maltodextrin + Sodium alginate & $5: 6$ & 8 \\
$\mathrm{~T}_{7}$ & Maltodextrin + Gum acacia & $5: 2$ & 8 \\
$\mathrm{~T}_{8}$ & Maltodextrin + Gum acacia & $5: 4$ & 8 \\
$\mathrm{~T}_{9}$ & Maltodextrin + Gum acacia & $5: 6$ & 8 \\
\hline
\end{tabular}

\subsection{Emulsion characterization}

\subsubsection{Emulsion zeta potential and droplet size}

The zeta potential and droplet size of the prepared emulsions were measured using Zeta nanosizer (Malvern-Aimil Instruments Private Limited, New Delhi, India) with a dynamic light scattering system. The emulsions were initially dispersed in distilled water, and the droplet size distribution was then measured until three constant readings were obtained.

\subsection{Microencapsulation by spray drying}

After preparation of emulsion, the emulsion was subjected to spray drying using a laboratory scale spray dryer Lab Plant SD-48 (Huddersfield, England), with a nozzle atomization system with $0.5 \mathrm{~mm}$ diameter nozzle. The emulsion was fed through a peristaltic pump where the pump rotation speed regulates the flow rate of feed solution to $16 \mathrm{~m} / \mathrm{s}$. The pressure of the compressed air for concurrent flow of spray dryer was adjusted to $2 \mathrm{~kg} / \mathrm{cm}^{2}$. Inlet and outlet air temperature were $160{ }^{\circ} \mathrm{C}$ and $70{ }^{\circ} \mathrm{C}$, respectively with aspirator speed of $1200 \mathrm{rpm}$.

\subsection{Encapsulated powders analysis}

\subsubsection{Encapsulation efficiency}

Encapsulation efficiency (EE) was determined according to the method reported by Bae and Lee (2008). Fifteen milliliters of hexane were added to $1.5 \mathrm{~g}$ of microcapsules in a glass jar with a lid, agitated for $2 \mathrm{~min}$, for the extraction of free oil, at room temperature. The solvent mixture was then filtered through a Whatman filter paper number 1 and the microcapsules collected was rinsed three times with $20 \mathrm{ml}$ of hexane. Then, the solvent was left to desiccate, at room temperature and $60{ }^{\circ} \mathrm{C}$, until constant weight. The non-encapsulated oil (surface oil) was determined by the mass difference among the initial clean flask and that containing the extracted oil residue (Jafari et al., 2008). Total oil was supposed to be equivalent to the initial oil which was presumed as flaxseed oil. Encapsulation efficiency (EE) was calculated as given below:

$$
\mathrm{EE}=\frac{\mathrm{TO}-\mathrm{SO}}{\mathrm{TO}} \times 100
$$

Where TO and SO is the total and surface oil content, respectively.

\subsubsection{Encapsulation yield}

The encapsulation yield of microcapsules, estimated as the ratio of the weight of microcapsules and the weight of total solids (including wall and core material) expressed as a percentage of yield (Che Man et al., 1999).

\subsubsection{Morphology and size}

Microcapsules were observed in a Scanning Electron Detector microscope (LEO Electron Microscopy, Oxford, England) working at $15 \mathrm{kV}$ and electron beam current of $100 \mathrm{pA}$. The samples were fixed directly on door-metallic specimens (stubs) of $12 \mathrm{~mm}$ diameter and then subjected to metallization (sputtering) with a thin layer of gold/palladium in a Sputter Coater SC7620 polaron (VG Microtech, England) at a coverage rate of $0.51 \AA / \mathrm{s}$ for $180 \mathrm{~s}$, with a current of $3.5 \mathrm{~mA}, 1 \mathrm{~V}$ and $2102 \mathrm{~Pa}$. After metallization, the samples were observed with magnifications of 4000, 5000 and 10,000. Image acquisition was performed by the LEO software, version 3.01.

\subsection{Statistical analysis}

The statistical difference between droplet size of emulsion and encapsulation efficiency and encapsulation yield of microcapsules for all the nine different combinations of wall material was determined using a two-way analysis of variance (ANOVA).

\section{Results}

\subsection{Emulsion zeta potential and droplet size}

The zeta potential analysis of emulsions (Table 2) shows that the values for maltodextrin and sodium caseinate, maltodextrin and sodium alginate, and maltodextrin and gum acacia combinations ranges from $-10.7 \mathrm{mV}$ to $-29.9 \mathrm{mV},-18.3 \mathrm{mV}$ to $-42.7 \mathrm{mV}$, and $-38.3 \mathrm{mV}$ to $-50.7 \mathrm{mV}$, respectively (Figure 1, Table 2). The particle charge for all the emulsions were kinetically stable, except for those produced with a combination of maltodextrin and gum acacia. The combination of maltodextrin and sodium caseinate was found to be more stable in comparison to other wall material combination. The combination of maltodextrin and sodium alginate shows that with increase or decrease in the concentration of sodium alginate results in the unstable emulsion.

Table 2: Zeta potential of $(\mathrm{mV})$ various combinations of emulsions

\begin{tabular}{|l|l|l|l|l|}
\hline Material & $\mathbf{5 : 2}$ & $\mathbf{5 : 4}$ & $\mathbf{5 : 6}$ & Stable/unstable \\
\hline M+SC & -29.9 & -11.3 & -10.7 & Stable \\
M+SA & -41.3 & -18.3 & -42.7 & Unstable \\
M+GA & -507 & -38.3 & -60.4 & Unstable \\
\hline
\end{tabular}




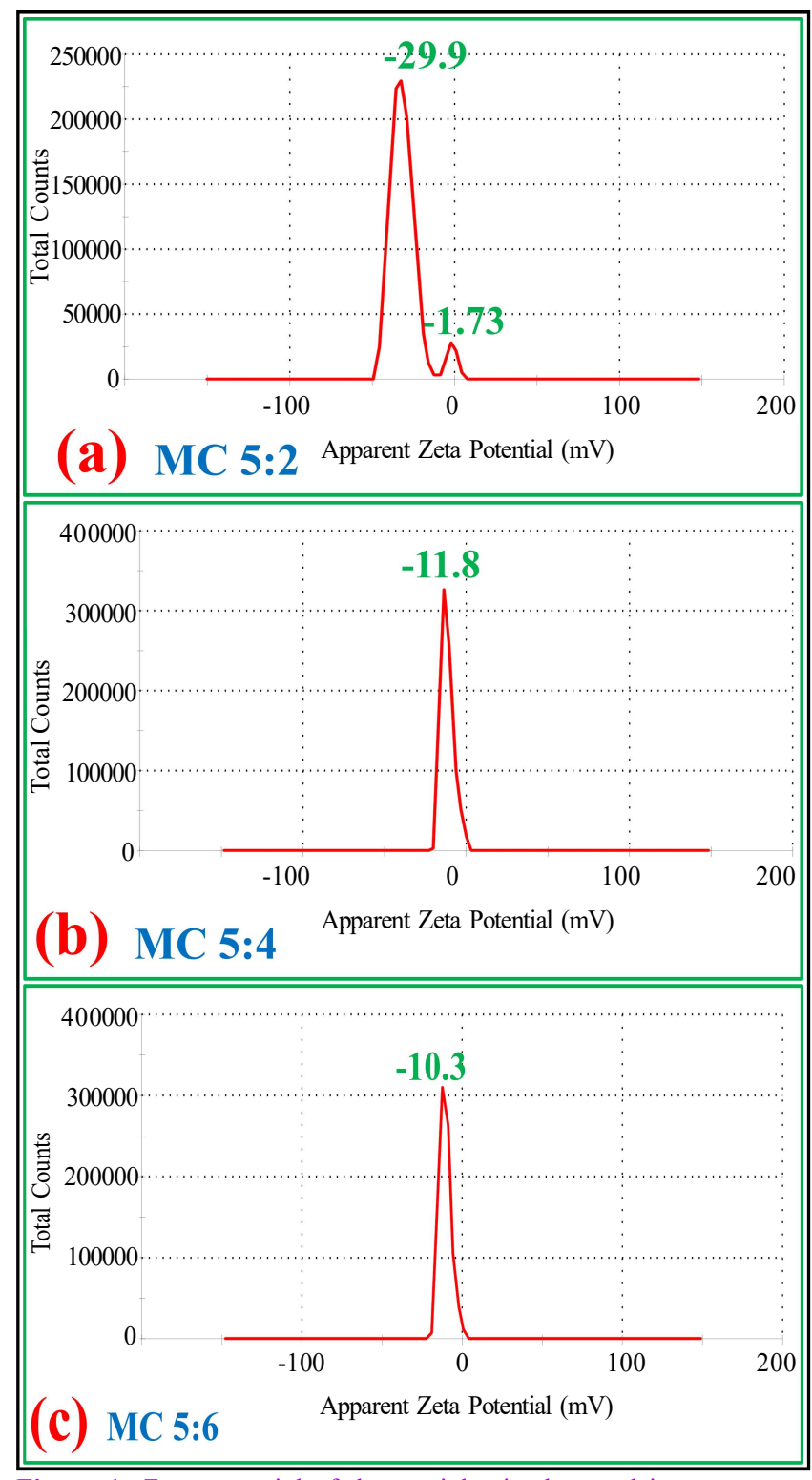

Figure 1: Zeta potential of the particles in the emulsion.

The droplet size distribution of the emulsions prepared with different wall material was shown in Table 3 and Figure 2. The emulsions prepared with a combination of maltodextrin and gum acacia $(5.44 \mu \mathrm{m})$ had the largest droplet size diameter, and those prepared with a combination of maltodextrin and sodium caseinate $(0.95 \mu \mathrm{m})$ had the smallest.

Table 3: Emulsion droplet size of various combinations of wall materials

\begin{tabular}{|l|l|l|}
\hline S.N. & Experimental Trials & Droplet size \\
\hline 1. & $\mathrm{~T}_{1}$ & $0.95 \mu \mathrm{m}$ \\
2. & $\mathrm{~T}_{2}$ & $0.87 \mu \mathrm{m}$ \\
3. & $\mathrm{~T}_{3}$ & $0.87 \mu \mathrm{m}$ \\
4. & $\mathrm{~T}_{4}$ & $0.35 \mu \mathrm{m}$ \\
5. & $\mathrm{~T}_{5}$ & $1.76 \mu \mathrm{m}, 5.36 \mu \mathrm{m}$ \\
6. & $\mathrm{~T}_{6}$ & $0.59 \mu \mathrm{m}, 5.20 \mu \mathrm{m}$ \\
7. & $\mathrm{~T}_{7}$ & $0.33 \mu \mathrm{m}, 2.11 \mu \mathrm{m}$ \\
8. & $\mathrm{~T}_{8}$ & $2.88 \mu \mathrm{m}$ \\
9. & $\mathrm{~T}_{9}$ & $1.03 \mu \mathrm{m}$ \\
\hline
\end{tabular}
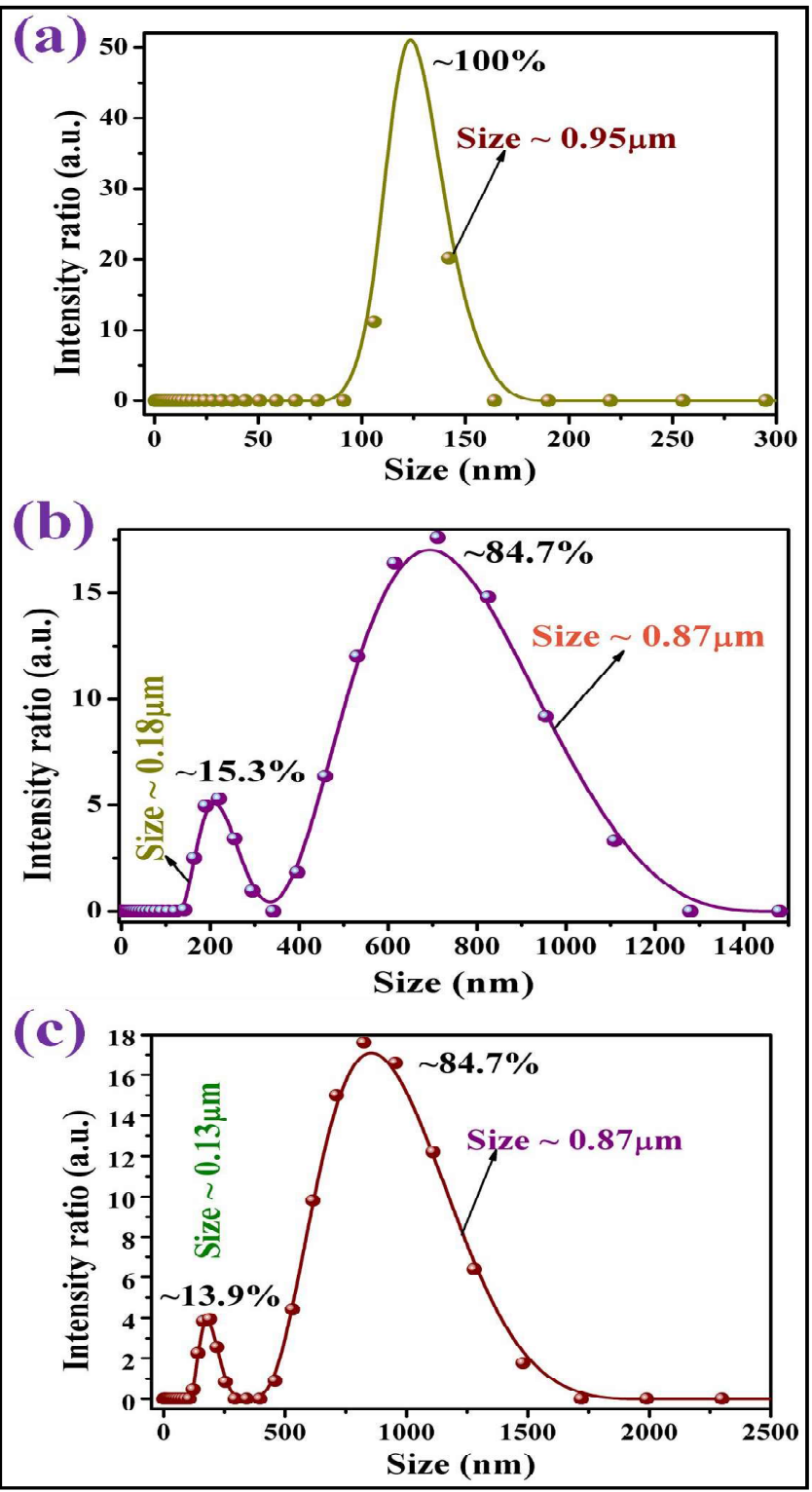

Figure 2: Particle size distribution of particles in different ratio (a) $5: 2$, (b) $5: 4$, (c) $5: 6$.

\subsection{Encapsulation Efficiency}

Encapsulation efficiency (EE) of all nine treatments was revealed in the Figure 3 and Table 4 . The encapsulation efficiency of experimental trial $\mathrm{T}_{2}(89.97 \%)$ was found to be higher accompanied by that of trial $\mathrm{T}_{5}(86.03 \%)$. The combination of maltodextrin and gum acacia shows reduced encapsulation efficiency amongst all the other combination of the wall material. The encapsulation efficiency of microcapsules depicts that, in the maltodextrin and sodium alginate combination, the encapsulation efficiency increases when the amount of maltodextrin and sodium alginate are approximately equal.

\subsection{Encapsulation Yield}

The encapsulation yield of all the nine flaxseed microcapsules explains that the combination of maltodextrin and sodium caseinate of ratio 5:2 and 5:4 proffers higher encapsulation yield of $28 \%$ and 
$24.21 \%$, respectively (Figure 3; Table 4). In maltodextrin and sodium alginate combination of ratio 5:4 confers the highest encapsulation yield of $23.20 \%$ in comparison to other ratios of the

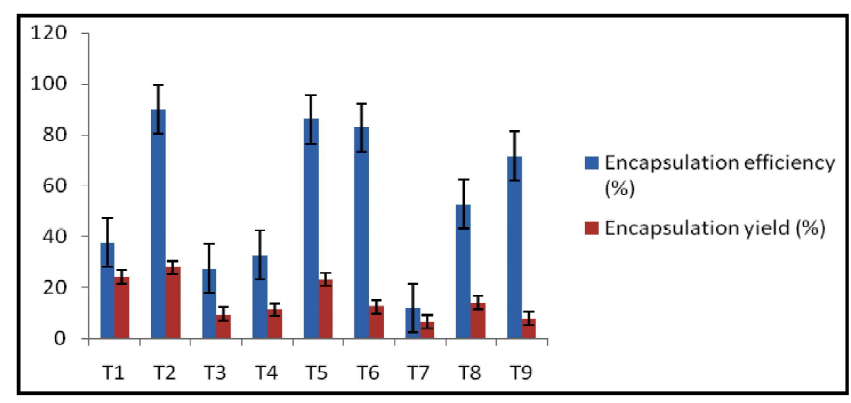

Figure 3: Encapsulation efficiency and encapsulation yield of flaxseed oil microcapsules Values are mean \pm SD $(n=3)$

\subsection{Morphology and size}

The external morphology and crystalline nature of the flaxseed microcapsules were revealed using a scanning electron microscope (SEM). Figure 4 explains the morphology and size of flaxseed microcapsules. The morphology of flaxseed microcapsules revealed that the microcapsules were spherical with no surface dents and a size range of 3.57-11.56 $\mu \mathrm{m}$. The microcapsules prepared from combination ratio of 5:6 of maltodextrin and sodium caseinate and maltodextrin and sodium alginate show that the capsules are hollow these were similar to microcapsules prepared from all the ratio of same combination. The encapsulation yield of maltodextrin and gum acacia combination was seen to be non-significant to other combination of wall material due to its larger particle size (Figure 3).

Table 4: Encapsulation efficiency in different treatments

\begin{tabular}{|l|l|l|l|}
\hline S.No. & Treatments & $\begin{array}{l}\text { Encapsulation } \\
\text { efficiency }(\%)\end{array}$ & Encapsulation yield (\%) \\
\hline 1 & $\mathrm{~T}_{1}$ & 37.68 & 24.21 \\
2 & $\mathrm{~T}_{2}$ & 89.97 & 28.00 \\
3 & $\mathrm{~T}_{3}$ & 27.32 & 9.48 \\
4 & $\mathrm{~T}_{4}$ & 32.71 & 11.31 \\
5 & $\mathrm{~T}_{5}$ & 86.03 & 23.20 \\
6 & $\mathrm{~T}_{6}$ & 82.76 & 12.48 \\
7 & $\mathrm{~T}_{7}$ & 12.09 & 6.552 \\
8 & $\mathrm{~T}_{8}$ & 52.82 & 13.85 \\
9 & $\mathrm{~T}_{9}$ & 71.62 & 7.80 \\
\hline
\end{tabular}

maltodextrin and gum acacia combination which indicates that the flaxseed oil is not encapsulated. The microcapsule of combination maltodextrin and sodium caseinate of ratio 5:4 shows uniform covering resulting in no crack on the surface of the microcapsules which thus limits the air incursion (Aghbashlo et al., 2012). The present study agrees with the study reported by Kolanowski et al. (2006) resulting in spherical microcapsules of fish oil. Other combinations show depression in the surface of microcapsules which is due to the breakdown of droplets by particle shrinkage during the process of drying.
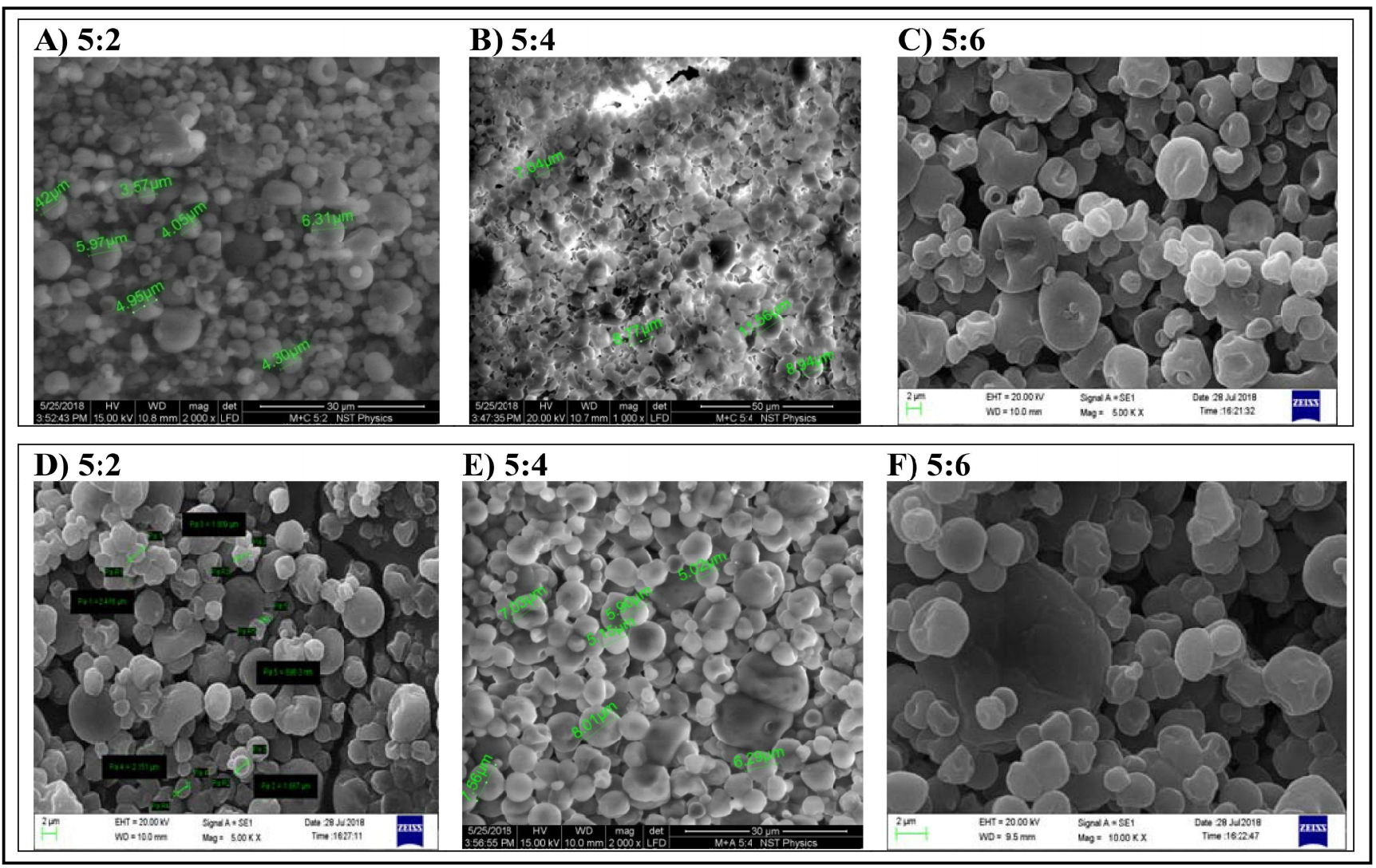

Figure 4: Morphology characteristics of flaxseed oil microcapsules in different treatments. A-C: Maltodextrin + Sodium Casinate D-F: Maltodextrin + Sodium Alginate 


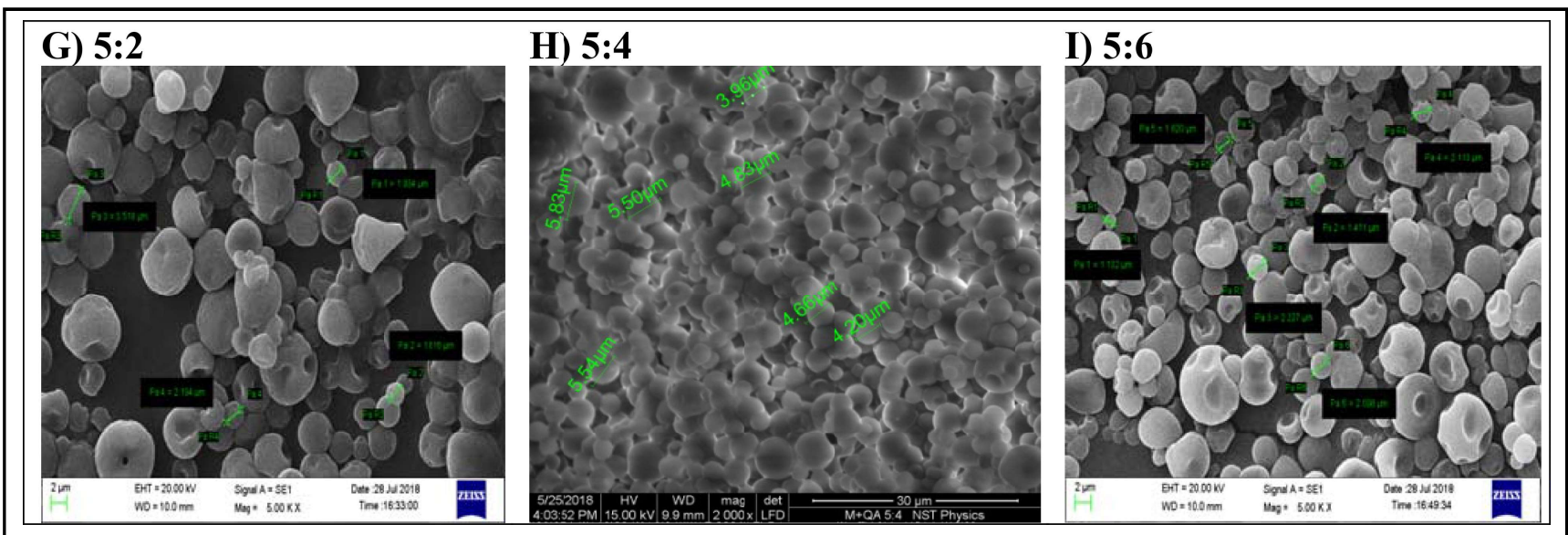

Figure 4: Morphology characteristics of flaxseed oil microcapsules in different treatments. G-I: Maltodextrin + Gum Acacia

\section{Discussion}

Oils are easily available and have been used from ancient time for medicinal purpose (Fehim et al., 2017). Zeta potential of emulsion confers data regarding the emulsion stability by establishing the efficient electric charge on the surface of the emulsion. The zeta potential of emulsion provides particle charge $(-10$ to $+10 \mathrm{mV}$ and -30 to $+30 \mathrm{mV}$ ) which act as stability determining factor. With the increase in the electrostatic repulsion between the particles, the stability of emulsion increased. The instability of emulsion produced with gum acacia was due to the unfolding of protein molecules at the droplet surface, which heightens the proteinprotein interaction, leading to flocculation during emulsification. The unfolding of protein units of the oil-water interface may lead to alters the secondary and tertiary structures and, consequently, exposure of their residues, which would be associated (-S-S linkages or disulfide linkages) within the primary globular structure, resulting in the formation of intermolecular interaction at the oil-water interface and flocculation (Tonon et al., 2012).

The encapsulation efficiency depicts the amount of oil that has been retained within the wall material, comparative to the surface oil present on microcapsules (Klinkesorn et al., 2006). Encapsulation efficiency is linked with emulsion stability as an increase in encapsulation efficiency results in increased stability (Ortega-Rivas et al., 2006). This statement agrees with the present research, both the trial $\mathrm{T}_{2}$ and $\mathrm{T}_{5}$ had high emulsion stability resulting in increased encapsulation efficiency. The encapsulation efficiency of the present research was comparable as described by Chan et al. (2011). Statistical data shows that the selection of wall material and oil concentration was a highly significant factor, for the encapsulation efficiency, though, the interaction of combination prepared from gum acacia $\left(\mathrm{T}_{7}, \mathrm{~T}_{8}, \mathrm{~T}_{9}\right)$ was not significant. The emulsion stability correlates with the encapsulation efficiency as the poor stability for combination maltodextrin and gum acacia resulted in lower encapsulation efficiency. The large droplet size indicates high surface oil content, which thus results in reduced encapsulation efficiency (Soottitantawat et al., 2003). The smaller emulsion droplet size results in increased stability of emulsion with adequate retention of active material (Carneiro et al., 2013; Jafari et al., 2008).

\section{Conclusion}

Flaxseed oil is known to be the rich vegetarian source of omega 3 fatty acid and have nutraceuticals used in prevention of cardiovascular diseases. The parameters like encapsulation efficiency, encapsulation yield and the emulsion stability was analyzed in the screening of wall material for the microencapsulation of flaxseed oil. The morphological characteristics reveal that the treatment $T_{2}$ covers the active material completely. The microencapsulation of flaxseed oil enhances its solubility resulting easy release of flaxseed oil. Moreover, microencapsulation influences the oxidative stability of the oil. Further research needs to carry out on fortification of various food products with flaxseed oil microcapsules, as this will have a positive impact on the overall health of the consumer.

\section{Acknowledgements}

Authors acknowledge Department of Biotechnology, Government of India for their financial support.

\section{Conflict of interest}

The authors declare that there are no conflicts of interest in the course of conducting the research. All the authors had final decision regarding the manuscript and decision to submit the findings for publication.

\section{References}

Aghbashlo, M.; Mobli, H.; Rafiee, S. and Madadlou, A. (2012). Optimization of emulsification procedure for mutual maximizing the encapsulation and exergy efficiencies of fish oil microencapsulation. Powder Technology, 225:107-117.

Ahn, J. H.; Kim, Y. P.; Lee, Y. M.; Seo, E. M.; Lee, K. W. and Kim, H. S. (2008). Optimization of microencapsulation of seed oil by response surface methodology. Food Chemistry, 107(1):98-105.

Bae, E. K. and Lee, S. J. (2008). Microencapsulation of avocado oil by spray drying using whey protein and maltodextrin. Journal of Microencapsulation, 25(8):549-560.

Calvo, P.; Lozano, M.; Espinosa-Mansilla, A. and González-Gómez, D. (2012). In vitro evaluation of the availability of $\varpi-3$ and $\varpi-6$ fatty acids and tocopherols from microencapsulated walnut oil. Food Research International, 48(1):316-321. 
Carneiro, H. C.; Tonon, R. V.; Grosso, C. R. and Hubinger, M. D. (2013) Encapsulation efficiency and oxidative stability of flaxseed oi microencapsulated by spray drying using different combinations of wall materials. Journal of Food Engineering, 115(4):443-451.

Chan, E. S.; Lim, T. K.; Voo, W. P.; Pogaku, R.; Tey, B. T. and Zhang, Z. (2011) Effect of formulation of alginate beads on their mechanical behaviour and stiffness. Particuology, 9(3):228-234.

Charve, J. and Reineccius, G. A. (2009). Encapsulation performance of proteins and traditional materials for spray dried flavors. Journal of Agricultural and Food Chemistry, 57(6):2486-2492.

Che Man, Y.B.; Irwandi, J. and Abdullah, W.J.W. (1999). Effect of differen types of maltodextrin and drying methods on physico chemical and sensory properties of encapsulated durian flavor. Journal of the Science of Food and Agriculture, 79(8):1075-1080.

Desai, K. G. and Park, H. J. (2005). Preparation of cross-linked chitosan microspheres by spray drying: Effect of cross-linking agent on the properties of spray dried microspheres. Journal of Microencapsulation, 22(4):377-395.

Fahim, M.; Shrivastava, B.; Shrivastava, A. K.; Ibrahim, M.; Parveen, R. and Ahmad S. (2017). Review on extraction methods, antioxidant and antimicrobial properties of volatile oils. Annals of Phytomedicine, 6(2):5-46.

Gharsallaoui, A.; Roudaut, G.; Chambin, O.; Voilley, A. and Saurel, R. (2007) Applications of spray-drying in microencapsulation of food ingredients: An overview. Food Research International, 40:1107-1121.

Jafari, S. M.; Assadpoor, E.; He, Y. and Bhandari, B. (2008). Encapsulation efficiency of food flavours and oils during spray drying. Drying Technology, 26(7):816-835.

Klinkesorn, U.; Sophanodora, P.; Chinachoti, P.; Decker, E. A. and McClements, D. J. (2006). Characterization of spray-dried tuna oil emulsified in two-layered interfacial membranes prepared using electrostatic layer-by-layer deposition. Food Research International, 39:449-457.

Kolanowski, W.; Laufenberg, G. and Kunz, B. (2004). Fish oil stabilisation by microencapsulation with modified cellulose. International Journal of Food Sciences and Nutrition, 55(4):333-343.
Mishra, S.; Arvind; Rai D. C. and Pandhi S. (2020). Process optimization for yogurt preparation incorporated with encapsulated Caesalpinia bonducella seed extract. Ann. Phytomed., 9(1):224-228.

Nesterenko, A.; Alric, I.; Silvestre, F. and Durrieu, V. (2013). Vegetable proteins in microencapsulation: A review of recent interventions and their effectiveness. Industrial Crops and Products, 42:469-479.

Ortega-Rivas, E.; Juliano, P. and Yan, H. (2006). Food powders: Physical properties, processing, and functionality. Ed: Springer Science and Business Media.

Rajeshwari, C.U.; Shobha R.I. and Andallu, B. (2014). Phytochemicals in diet and human health with special reference to polyphenols. Ann. Phytomed., 3(2):4-25

Shibasaki, A.; Irimoto, Y.; Kim, M.; Saito, K.; Sugita, K.,; Baba, T. and Sugo, T. (1999). Selective binding of docosahexaenoic acid ethyl ester to a silver ion loaded porous hollow fiber membrane. Journal of the American Oil Chemists' Society, 76(7):771-775.

Soottitantawat, A.; Takayama, K.; Okamura, K.; Muranaka, D.; Yoshii, H.; Furuta, T. and Linko, P. (2005). Microencapsulation of 1-menthol by spray drying and its release characteristics. Innovative Food Science and Emerging Technologies, 6(2):163-170.

Soottitantawat, A.; Yoshii, H.; Furuta, T.; Ohkawara, M. and Linko, P. (2003) Microencapsulation by spray drying: Influence of emulsion size on the retention of volatile compounds. Journal of Food Science, 68(7): 2256-2262.

Tonon, R. V.; Pedro, R. B.; Grosso, C. R. and Hubinger, M. D. (2012). Microencapsulation of flaxseed oil by spray drying: Effect of oil load and type of wall material. Drying Technology, 30(13):1491-1501.

Tyagi, V. V.; Kaushik, S. C.; Tyagi, S. K. and Akiyama, T. (2011). Development of phase change materials based microencapsulated technology for buildings: A review. Renewable and Sustainable Energy Reviews, 15(2):1373-1391.

Velasco, J.; Dobarganes, M. C. and Márquez-Ruiz, G. (2000). Application of the accelerated test Rancimat to evaluate oxidative stability of dried microencapsulated oils. Grasasy Aceites, 51(4):261-267.

Citation Dinesh Chandra Rai, Arvind and Vinod Kumar Paswan (2020). Optimization of coating material for encapsulation of flax seed oil containing omega-3 fatty acids. Ann. Phytomed., 9(2):277-282. http://dx.doi.org/10.21276/ap.2020.9.2.27 